\title{
HIDDEN MATERNAL EATING DISORDER AND NEONATAL PSEUDO-BARTTER : LOOK IN THE MIRROR !
}

P. Maton, C. Gobert, A. François-Adant, A. Marguglio, W. Marion, S. Smeets, J.-P. Langhendries

NICU, CHC St Vincent, Rocourt-Liège, Belgium

Background: Bartter and pseudo-Bartter syndromes share the features of metabolic alkalosis, hypokalaemia and hypochloremia. The former is a well identified primary renal disease, due to defects in ascending Henle's loop chloride reabsorption. The latter is secondary to chloride depletion of various aetiologies (chronic vomiting, diuretic abuse, prostaglandin infusion,...).

Methods: 2 cases of neonatal pseudo-Bartter were identified at birth, where the diagnosis was also rapidly made in the mother afterwards, in the context of an eating disorder (table).Chloriduria, reninemia and aldosteronemia were normal in both neonates. Rehydration and ionic supplementation allowed for complete resolution of the abnormalities observed. The clinical course was thereafter uneventful and longer follow-up was reinsuring.

\begin{tabular}{|l|l|l|}
\hline & patient 1 (Newborn/mother) & patient 2 (Newborn/mother) \\
\hline $\mathrm{pH}$ & $7.46 / 7.53$ & $7.54 / 7.62$ \\
\hline $\mathrm{HCO}-(\mathrm{mEq} / \mathrm{l})$ & $53 / 51$ & $59 / 50.8$ \\
\hline $\mathrm{K}(\mathrm{mEq} / \mathrm{l})$ & $2.2 / 1.4$ & $1.8 / 1.7$ \\
\hline $\mathrm{Cl}(\mathrm{mEq} / \mathrm{l})$ & $66 / 76$ & $90 / 86$ \\
\hline
\end{tabular}

[initial blood values]

Discussion: Chloride depletion, the initial trigger of pseudo-Bartter, and extreme hypokalaemia may affect the foetus through the placenta. Bi-directional transplacental chloride diffusion results in a low- chloride foetal regimen. Placental K+-ATPase activity, normally controlling the foetal kalaemia, is probably downregulated due to low maternal values. This "mirror effect" explains the pseudo-Bartter syndrome present in neonates born to mothers with eating disorders, which might put them at risk of precocious inadvertent death.

Conclusion: Mother-infant dyads should be investigated together in neonatal electrolytes disturbances suggestive of pseudo-Bartter. It could be more frequent than thought. 